Rev. Elet. em Gestão, Educação e Tecnologia Ambiental (e-ISSN: 2236-1170)

\title{
ECONOMIA SOLIDÁRIA DE SANTA MARIA: ESTUDO DA DIFUSÃO DE SEUS VALORES E PERFIL DOS PARTICIPANTES
}

\section{SOLIDARITY ECONOMY OF SANTA MARIA: A STUDY OF THE SPREAD OF ITS VALUES AND PROFILE OF PARTICIPANTS}

\author{
Tatiane Pelegrini ${ }^{1}$, Rodrigo Klein Lorenzoni ${ }^{1}$, Eduardo Rodrigues Sanguinet ${ }^{1}$, Andréa Cristina Dörr ${ }^{2}$, \\ Marivane Vestena Rossato ${ }^{3}$, Ana Carolina Kohlrausch Klinger ${ }^{4}$ \\ ${ }^{1}$ Graduandos do Curso de Ciências Econômicas da Universidade Federal de Santa Maria. \\ E-mail: tatikpelegrini@gmail.com; lorenzoni.rodrigo@gmail.com; eduardorodrigues43@gmail.com \\ ${ }^{2}$ Professora Adjunta do Departamento de Ciências Econômicas da Universidade Federal de Santa Maria. \\ E-mail: andreadoerr@yahoo.com.br \\ ${ }^{3}$ Professora Adjunta do Departamento de Ciências Contábeis da Universidade Federal de Santa Maria. \\ E-mail: marivest@gmail.com \\ ${ }^{4}$ Acadêmica do Programa para Formação de Professores pela Universidade Federal de Santa Maria. \\ E-
} mail: anaklinger@zootecnista.com.br

http://dx.doi.org/10.5902/223611708798

\section{RESUMO}

O Comércio Justo surge como uma área de aplicação de conceitos de sustentabilidade e preço justo através de iniciativas como a Feira Solidária no município de Santa Maria-RS, que desde 1994 constitui um campo onde os valores da Economia Solidária possam se difundir. Este trabalho engloba uma pesquisa onde foram entrevistados 30 expositores e 55 consumidores que frequentaram a 5a Feira de Economia Solidária do Mercosul de Santa Maria no ano de 2011 a fim de caracterizar os agentes e processos envolvidos. Os resultados mostram que os consumidores possuem conhecimentos específicos sobre economia solidária, além de uma elevada restrição orçamentária e escolaridade, o que permite que seja praticado um "consumo responsável". Para os expositores, constatou-se que estes não despendem tempo na pesquisa sobre Economia Solidária, além de apresentarem níveis de escolaridade e renda média mensal abaixo dos consumidores que frequentam a Feira. A maioria dos expositores provém de municípios do Rio Grande do Sul, apontando que ocorrem falhas de divulgação a nível nacional e internacional. Conclui-se que a Economia Solidária já possui vias para que seus valores possam se expandir, além de um crescente público consumidor preocupado com o desenvolvimento de formas de produção que propaguem sustentabilidade ambiental e a garantia de preços justos.

Palavras-chave: cooperativismo, economia solidária, fair trade, feira solidária

\begin{abstract}
Fairtrade emerges as an area where concepts such as sustainability and fair price are applied through initiatives like the Solidarity Fair in Santa Maria-RS, held since 1994, and constitute a field where the values of the Economic Solidarity are spread. This work includes a survey of 30 exhibitors and 55 consumers attending the 5th Fair of Solidarity Economic Mercosur Santa Maria in 2011, in order to characterize the processes and agents involved. The results show that consumers have specific knowledge about economic solidarity, and a high budget constraint and schooling, which allow them to practice a "responsible consumption". For the exhibitors, it was found that they do not spend much time on research on Economics of Solidarity, and have income and education levels below the monthly average consumers who attend the Fair. Most exhibitors also come mostly from municipalities of the Rio Grande do Sul state, noting that disclosure failures occur nationally and internationally. It is concluded that the Economic Solidarity has its own way to expand values, and a growing consumer audience concerned with the development of production forms that spread environmental sustainability and ensure fair prices.
\end{abstract}

Keywords: cooperativism, fairtrade, solidarity economic, solidarity fair 
Rev. Elet. em Gestão, Educação e Tecnologia Ambiental (e-ISSN: 2236-1170)

\section{INTRODUÇÃO}

O comércio justo surgiu na década de 60 e constitui uma iniciativa que possui a capacidade de promover a justiça social e econômica, o desenvolvimento sustentável, o respeito pelas pessoas e pelo meio ambiente, através do aumento da consciência dos consumidores, da educação, da informação e da ação política. O Fair Trade baseia-se, prioritariamente, em relações transparentes e co-responsáveis entre os diversos elos da cadeia produtiva, elencando como prioridades os benefícios, como competitividade e sustentabilidade aos pequenos e médios produtores (LIMA et al., 2012).

O Fair Trade, reconhecido como uma das iniciativas de Economia Solidária é identificado como uma alternativa ao comércio tradicional. Essa iniciativa é mantida e fortalecida por uma parcela de consumidores dispostos a buscar uma alternativa para a desigualdade e injustiça, recompensando empresas com objetivos sociais, preocupações ambientais e capacidade de melhorar as condições de trabalhadores dos países menos desenvolvidos (PÉREZ et al., 1999). Os consumidores praticam o que se chama de "consumo responsável" definido como a capacidade de cada pessoa ou instituição pública ou privada escolher serviços e produtos que contribuam, de forma ética e de fato, para a melhoria de vida de cada um, da sociedade e do ambiente.

No Brasil, a economia solidária é um fenômeno recente, pois a primeira publicação organizada sobre o tema surgiu no ano de 1994 e o termo economia solidária só passou a ser difundido ao final da década de 90. Paralela a esta difusão, também ocorreu a multiplicação das instituições dedicadas a promover a economia solidária (VIEIRA, 2005). A Feira de Economia Solidária de Santa Maria surgiu no mesmo ano em que houve a primeira publicação acadêmica sobre o tema, demonstrando que a evolução do debate acerca da Economia Solidária no Brasil tem ocorrido no mesmo período que a propagação da Feira realizada no interior do estado do Rio Grande do Sul.

A Economia Solidária amadurece no Brasil nos anos 90, no âmbito das pesquisas sobre reestruturação produtiva, processo de trabalho e organização da produção que evidenciaram o surgimento de novas relações entre os atores sociais em um período de intensas mudanças econômicas e sociais, como, a elevada inflação no início da década e a desigualdade de renda. Nesta época ocorrem campanhas de combate à fome, à miséria, ao desemprego, e sobre políticas públicas visando reduzir a exclusão social (DAGNINO, 2002).

Segundo Singer (2002, p. 13) "a economia solidária é uma criação em processo contínuo de trabalhadores em luta contra o capitalismo. Como tal, ela não poderia preceder o capitalismo industrial, mas o acompanha como uma sombra, em toda a sua evolução". O mesmo autor relata que a Economia Solidária é uma forma de restaurar a igualdade que foi abalada pelo processo de capitalista de produção através da associação "entre iguais" onde fosse implantado um processo de autogestão em cooperativas, em que onde o poder decisório e a organização fossem igualitários.

Desta forma, presencia-se, através da Economia Solidária, formas alternativas que vislumbram quebrar o ciclo de crescimento da pobreza e da exclusão social, causadas pelos programas liberais globalizados, que precisam ser consideradas ao se debater as futuras políticas de desenvolvimento, sobretudo dos países chamados periféricos. Se o tema da Economia Solidária 


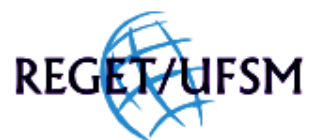

PELEGRINI et all , v(11), no 11, p. 2399-2406, JUN, 2013.

Rev. Elet. em Gestão, Educação e Tecnologia Ambiental (e-ISSN: 2236-1170)

servir para estas reflexões e práticas, ajudará em muito na busca de alternativas ao processo de desenvolvimento brasileiro (OLIVEIRA, 2003).

Consistindo em uma forma de produção diferenciada, é relevante que os agentes econômicos envolvidos conheçam os estudos e novidades sobre a área, para que os ideais desta organização econômica sejam difundidos e obtenham maior aceitação na sociedade. A realização da Feira de Economia Solidária de Santa Maria - RS colabora de forma fundamental para a realização destes objetivos, transformando-se em um pólo de irradiação de princípios que cada vez mais são valorizados e focalizados no campo econômico.

Portanto, o estudo das condições dos agentes da feira se faz de prima importância para conhecer as medidas futuras a serem tomadas para que a divulgação, tanto da feira quanto da forma de produção, sejam mais efetivas. $O$ trabalho tem objetivo de acompanhar a evolução que ocorre no segmento da Economia Solidária. Também se objetiva descrever os padrões de comportamento dos consumidores e os padrões de comercialização por parte dos produtores e vendedores destes tipos de bens mediante a aplicação de questionários em um evento característico como a Feira de Economia Solidária de Santa Maria, realizada no ano de 2011.

\section{METODOLOGIA}

\section{Caracterização da pesquisa}

Neste trabalho, foi realizada uma pesquisa de natureza aplicada, de caráter descritivo. "As pesquisas deste tipo têm como objetivo primordial a descrição das características de determinada população ou fenômeno ou estabelecimento de relações entre variáveis" (GIL, 1995, p. 45). O método de procedimento adotado neste estudo é o estatístico, que fornecerá informações quantificáveis e qualificáveis para a análise do comportamento dos consumidores e feirantes da 5a Feira de Economia Solidária do Mercosul.

\section{Fonte dos dados}

Os dados apresentados são de natureza primária e foram obtidos através de um levantamento, com questionários aplicados diretamente aos consumidores e feirantes. Segundo Gil (1995), os levantamentos podem ser de dois tipos: recolhimento de informações sobre todo o universo pesquisado, tendo-se um censo; ou seleção, mediante procedimentos estatísticos, de uma amostra significativa de todo o universo, denominado levantamento por amostragem. Neste trabalho, faz-se uso do levantamento por amostragem, devido à impossibilidade de se atingir toda a população para a coleta dos dados. A coleta dos dados deu-se mediante formulários semiestruturados constituído de perguntas abertas e fechadas.

\section{Amostragem}

A amostragem é uma ferramenta estatística utilizada quando a população - conjunto total dos elementos que se busca analisar - é composta por um número muito grande de 


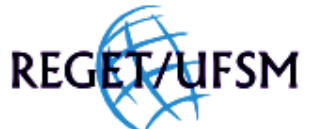

PELEGRINI et all , v(11), no 11, p. 2399-2406, JUN, 2013.

Rev. Elet. em Gestão, Educação e Tecnologia Ambiental (e-ISSN: 2236-1170)

elementos, o que impossibilita o acesso a toda a população para a coleta dos dados. Assim, uma amostra é selecionada, com número e característica significativos de elementos dentro da população, para que os resultados da amostra sejam suficientemente informativos para se inferir conclusões a cerca de parâmetros de toda a população em análise.

Como não é possível saber o número exato de clientes que o evento possui, a população em questão será considerada como população infinita e o tamanho da amostra a ser entrevistada será calculado conforme Barbetta (2008) a partir da amostragem aleatória simples, dada pela Equação 1.

$$
n=\left(\frac{t_{\delta} \frac{\alpha}{z} \times s}{e_{0}}\right)^{2}
$$

Onde:

$\mathrm{n}=$ tamanho mínimo da amostra calculada;

$t_{\delta, \frac{\alpha}{2}}=$ valor de $t_{\text {tab }}$ admitindo $\alpha=10 \%$;

$\mathrm{s}=$ desvio-padrão obtido através da amostra piloto;

$\mathrm{e}_{0}=$ erro amostral, obtido com os dados da amostra piloto.

As variáveis de desvio-padrão e erro amostral foram obtidas através da pesquisa piloto, que foi realizada com 30 feirantes e 30 visitantes da feira. Além de obter estas variáveis, a pesquisa piloto objetivou verificar a aplicabilidade do questionário e o tempo estimado para respondê-lo, assim como os ajustes que serão necessários realizar.

O tamanho mínimo das amostras calculado visando-se atingir um nível de significância de $90 \%$ foi de 30 expositores e 55 visitantes.

\section{RESULTADOS E DISCUSSÃO}

\section{Levantamento de dados dos expositores}

De um total de 30 expositores consultados, constatou-se que os mesmos advêm de 18 cidades do Rio Grande do Sul, sendo que a maioria, aproximadamente $25 \%$, é de Santa Maria-RS, cidade onde é realizada a Feira Solidária. Os demais expositores se distanciam de sua cidade até a feira variando de 17 (Itaara-RS) a $700 \mathrm{Km}$ (Santa Helena-RS). Dessa forma infere-se que a grande maioria provém da região central do Rio Grande do Sul.

Os dados também revelam que o gênero dos expositores é perfeitamente distribuído ente homens e mulheres (15 indivíduos de cada sexo). Portanto, o resultado mostra igualdade entre os gêneros na Economia Solidária, excluindo a predominância do sexo masculino nas atividades de comercialização.

Outro resultado interessante é a média elevada de idade entre os expositores, de aproximadamente, 42,33 anos, com desvio padrão de 19 a 79 anos. Também se denota que 


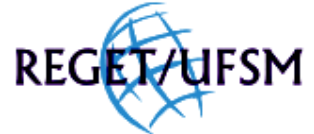

PELEGRINI et all , v(11), no 11, p. 2399-2406, JUN, 2013.

Rev. Elet. em Gestão, Educação e Tecnologia Ambiental (e-ISSN: 2236-1170)

raramente há distinção entre as funções de produção e venda. Em apenas um quarto das propriedades ocorre esta distinção, nas outras, as funções se sobrepõem.

O estado civil dos expositores é predominantemente casados, pois $75 \%$ dos mesmos se encontram em uma relação conjugal estável. O número de solteiros é de $15 \%$, e de viúvos e separados é inexpressivo. O número de filhos por expositores é, em média, de 1,63 filhos. Este número está levemente abaixo da taxa de fecundidade total do Brasil, que segundo o IBGE, em seu censo realizado em 2010, apontou uma taxa de 1,90.

O nível de escolaridade entre os vendedores apresenta uma média de 9,5 anos de estudo, com desvio padrão de 16 a 5 anos entre os expositores e a média de escolaridade varia entre o ensino fundamental incompleto até o ensino superior completo. Destaca-se também que um terço dos entrevistados possui uma atividade de renda extra, como por exemplo, aposentadoria, funcionalismo público, artesanato, entre outros, demonstrando que, em muitos casos, as famílias envolvidas com economia solidária precisam recorrer a outras atividades que envolvam atividades de maior rendimento e menor risco.

Em alguns casos, os rendimentos brutos mensais da família oriundos da atividade agrícola são menores que o salário mínimo, fato que representa um poderoso empecilho à continuidade da atividade. De um modo geral, porém, o rendimento mensal médio se encontra entre $\mathrm{R} \$$ 2.081,16, ou seja, pouco mais que três salários mínimos.

Dentre os expositores abordados, todos trabalham com produtos de cunho solidário a mais de um ano, numa média de 7,5 anos por produtor. Este resultado demonstra certa tradição por parte das famílias no cultivo e comercialização destes bens. Apesar da continuidade apresentada nas atividades, poucos expositores se ocupam de pesquisas e aquisição de conhecimentos sobre o Comércio Justo com periodicidade semanal $(6,65 \%)$ e mensal (36,65\%), demonstrando uma baixa taxa de P\&D por parte dos empresários rurais.

De fato, grande parte dos comerciantes não possui conhecimento do real significado do Comércio Justo - aproximadamente, um terço dos entrevistados não consegue descrever detalhadamente as atividades que praticam. Os expositores que responderam, argumentaram principalmente que a idéia de justiça no comércio diz respeito aos preços cobrados, não envolvendo outras variáveis como sustentabilidade e qualidade de vida.

Deste modo, quais são as principais razões que trazem comerciantes desta modalidade de produtos a Feira Solidária? Segundo os expositores, a receptividade que os produtos encontram por parte dos consumidores é o principal motivo. Citam-se ainda o contato com diferentes pessoas e colegas de trabalho, além de gerar uma renda extra para a família ou auxiliar amigos e demais familiares, trocar de experiências sem intermediários ou burocracia excessiva. Os produtos são expostos e divulgados de forma natural, por parte dos próprios produtores que participam desde o cultivo até as vendas finais dos bens comercializados.

Apesar das vantagens apontadas pelos expositores, o tempo em que estes participam da Feira Solidária é mais baixo do que o tempo trabalhado com estes produtos, cerca de 4,7 anos a menos do que o tempo médio dedicado à atividade. Uma das possíveis razões para isso são as falhas de divulgação para com os produtores, ou talvez, a participação na Feira não seja uma atividade tão lucrativa como o trabalho em outros clientes ou locais comerciais, por exemplo, supermercados ou cooperativas. 


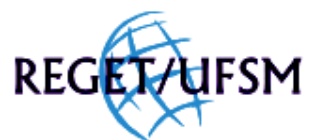

PELEGRINI et all , v(11), no 11, p. 2399-2406, JUN, 2013.

Rev. Elet. em Gestão, Educação e Tecnologia Ambiental (e-ISSN: 2236-1170)

Afirma-se que por parte dos expositores, a permanência na comercialização de produtos solidários se deve em função de trazer rendimentos extras à família, caracterizando esta atividade como tradicional e revestida de liberdade entre os trabalhadores rurais, que podem permanecer no meio rural, gozando de rendimentos compensatórios pela atividade que executam, além de integração comercial e profissional.

\section{Levantamento de dados dos consumidores}

De um total de 55 consumidores abordados pela pesquisa, $50 \%$ é proveniente do município de Santa Maria-RS, local onde é realizada a Feira Solidária, aproximadamente. Os demais frequentadores da feira dividem-se em 19 diferentes cidades.

Apesar de ser reconhecida como uma Feira do Mercosul, entre os entrevistados, apenas três são estrangeiros, um consumidor é advindo do Uruguai, um da Argentina e outro da Itália. Este resultado parcial indica que poderia haver maior participação entre os consumidores dos países integrantes desta união comercial, sendo necessária uma maior divulgação da feira. Dentro das fronteiras do Brasil, encontra-se maior variação da procedência dos consumidores; dois consumidores dos 55 entrevistados são naturais do Espírito Santo, três de Minas Gerais e um apenas do Paraná e Santa Catarina, ou seja, as regiões Sudeste e Sul são as únicas que participam da Feira em questão.

Com relação a análise dos dados socioeconômicos dos frequentadores da Feira Solidária, a maioria é composta por mulheres (70\%), com idade média de 42.9 anos, o que é praticamente igual à idade dos expositores supracitados. Quanto ao status profissional, destaca-se grande incidência de estudantes entre os mesmos (10\%), aposentados (10\%) e empregados regulares (76\%).

Tanto pela média de idades e como pelas atividades profissionais desempenhadas pelos visitantes da Feira Solidária, pode-se inferir que a Economia Solidária não é muito apreciada pelo público jovem, o que revela que esse público demonstra pouca curiosidade acerca da origem dos produtos que consome. De fato, ao entrevistar os consumidores, cerca de $35 \%$ do público afirmou que desconhecia o real significado do Comércio Justo, demonstrando que a qualidade e diversificação dos produtos são o principal foco para a atração de compradores.

$\mathrm{Na}$ economia, a restrição física conhecida como "lei da escassez" ou, igualmente, produção máxima de bens e serviços com os recursos disponíveis de cada sociedade é entendida como uma condição necessária para a produção de bens com recursos limitados em função de satisfazer as ilimitadas necessidades humanas. É preciso recordar que a escassez existe se houver um demanda para a aquisição de bens (PINDYCK \& RUBINFIELD, 2005).

Pelos conceitos abordados na Microeconomia um bem é demandado porque ele é capaz de oferecer utilidade aos consumidores, portanto, é a capacidade que um bem tem de satisfazer uma necessidade humana. Segundo a Teoria do Consumidor, um dos principais fatores que influencia na demanda é a renda ou restrição orçamentária. Na amostra de consumidores, a renda média auferida demonstrou-se surpreendentemente elevada, em torno de $\mathrm{R} \$ 2.299 .72$ ou aproximadamente, quatro salários mínimos. A renda dos consumidores da Feira Solidária é 


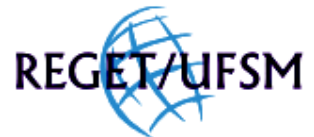

PELEGRINI et all , v(11), no 11, p. 2399-2406, JUN, 2013.

Rev. Elet. em Gestão, Educação e Tecnologia Ambiental (e-ISSN: 2236-1170)

superior a renda mensal brasileira, que é de $\mathrm{R} \$ 668,00$, segundo o Instituto Brasileiro de Geografia e Estatística, em 2010.

Assim como a renda média, a escolaridade também mostrou-se elevada e em torno de 12,4 anos de estudo, o que corresponde ao ensino médio completo, diferindo da escolaridade dos expositores, sendo esta última inferior em aproximadamente três anos. A alta taxa de escolaridade aliada a uma faixa de renda também elevada, permite classificar os frequentadores da Feira Solidária como consumidores que avaliam com mais critérios os bens que consomem, não é apenas os preços que pesam nas decisões dos consumidores, mas também a qualidade e origem dos produtos.

Grande parte dos consumidores (40\%) dedica-se à pesquisa específica sobre o Comércio Justo e é capaz de definir corretamente o que ele representa, como um novo tipo de mercado que proporciona iguais oportunidades às pessoas por ele envolvidas não agredindo as pessoas e o meio ambiente.

Deste modo, além do escopo do Comércio Justo, é a possibilidade de aquisição de produtos sustentáveis e ecológicos o principal motivo que leva os consumidores a frequentar a Feira Solidária, $23 \%$ do público abordado, afirma que não adquire produtos desta qualidade em outros locaisem parte alguma a não ser na própria Feira Solidária de Santa Maria-RS. O restante dos consumidores realmente possui o hábito de consumir bens ecológicos visitando outras feiras, cooperativas, mercados que oferecem estes bens, além de contatar diretamente com os produtores.

\section{CONCLUSÕES}

É através de iniciativas que valorizem a preservação do meio ambiente e dos laços de cooperativismo na produção de bens de qualidade diferenciada, como no caso da Economia Solidária, que surge uma nova cultura de consumo mundial, onde a consciência aliada à educação e responsabilidade no ato de comprar bens tem um olhar mais crítico sobre o futuro.

Do lado dos expositores, as atividades produtivas da Economia Solidária não geram renda suficiente para que as famílias dediquem-se exclusivamente à atividade, explicando o porquê do baixo nível de pesquisa e aprimoramento de sua área. Os comerciantes revelam ter um nível de renda mensal média per capita e escolaridade abaixo do nível médio dos consumidores da Feira nos referidos itens

Os consumidores se dedicam a pesquisas sobre o Comércio Justo, e, valorizam a qualidade e a origem dos produtos que consomem, comportamento este, que justifica também a alta renda média per capita auferida mensalmente, aliada a altas taxas de escolaridade. Todas as características apontadas pela pesquisa sobre os consumidores convergem aos preceitos do Fair Trade, constatando a conscientização e a responsabilidade nos atos de consumir. 


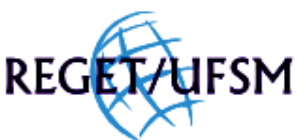

PELEGRINI et all , v(11), no 11, p. 2399-2406, JUN, 2013.

Rev. Elet. em Gestão, Educação e Tecnologia Ambiental (e-ISSN: 2236-1170)

\section{REFERÊNCIAS BIBLIOGRÁFICAS}

AGUIAR, L. K.; BARCELLOS, M. D.; VIEIRA, L. M. Understanding the Coordination Mechanisms in a Fair Trade Fruit

Supply Chain. Journal of Operations and Supply Chain Management, v. 3, n. 2, p. 13 - 25, 2009.

BARBETTA, P. A. Estatística Aplicada às Ciências Sociais. 7. ed. Florianópolis: Editora da UFSC, 2008.

DAGNINO, R. Em direção a uma Estratégia para a redução da pobreza: a Economia Solidária e a adequação Sóciotécnica. Organização dos Estados Ibero-americanos, 2002.

GIL, A. C. Métodos e Técnicas de Pesquisa Social. 4. ed. São Paulo: Editora Atlas, 1995.

IBGE. INSTITUTO BRASILEIRO DE GEOGRAFIA E ESTATÍstICA. Censo demográfico de 2010. Disponível em < http://www.censo2010.ibge.gov.br/>. Acesso em: 22 ago. 2010

LIMA, J. E. S.; SCHMIDT, G. C.; LIMA, S. M. M. Potencialidades e limites do comércio justo: Política pública para o consumo consciente. Revista InterSciencePlace. 22. ed., v. 1, 2012.

OLIVEIRA, B. A. M. Economia solidária e o cooperativismo popular: da gênese aos desafios atuais. Revista Proposta, n. 97, 2003.

PÉREZ, J. T.; RICO, P. N.; ARECHAGA, A. L. Para entender el comercio justo. Espanica, n. 1, p. 5- 23, 1999.

PINDYCK, R, S.; RUBINFELD, D, L. Microeconomia. São Paulo: Pearson Prentice Hall, 6. ed., 2005.

SANTOS, B. S.; RODRÍGUEZ, C. Introdução: para ampliar o cânone da produção In: SANTOS, B. de S. Produzir Para Viver: Os Caminhos da Produção não Capitalista. Rio de Janeiro: Civilização Brasileira, 2002. 23-77 p.

SIMÕES, C. P. Responsabilidade social e cidadania: conceitos e ferramentas. Brasília, 2008.

SINGER, P. Introdução a Economia Solidária. Fundação Perseu Abramo, 2003. 127 p.

SINGER, P. A recente ressurreição da economia solidária no Brasil. In: SANTOS, B. de S. Produzir para viver: oS caminhos da produção capitalista. Rio de Janeiro: Civilização Brasileira, 2002.

VIEIRA, F. M. Coerência e aderência da economia solidária: Um estudo de caso dos coletivos de produção do MST em Mato Grosso do Sul. Tese de Doutorado. 2005. 460 f. Tese (Doutorado em Ciências Econômicas), Universidade de São Paulo, São Paulo, 2005. 